\title{
Diagnostic value of serum adenosine deaminase in Type 2 diabetic patients
}

\author{
Kundu D. ${ }^{1}$, Sen S. ${ }^{2 *}$, Paul A. ${ }^{3}$, Chatterjee A. ${ }^{4}$, Sarkar P. ${ }^{5}$, Chakrabarti I. ${ }^{6}$ \\ DOI: https://doi.org/10.17511/ijmrr.2019.i01.01
}

\footnotetext{
1 Dipankar Kundu, Associate Professor, Department of Biochemistry, Medical College, Kolkata, West Bengal, India.

2* Santanu Sen, Associate Professor, Department of General Surgery, Medical College, Kolkata, West Bengal, India.

3 Aniket Paul, Final Year PGT, Department of Biochemistry, Medical College, Kolkata, West Bengal, India.

${ }^{4}$ Amrita Chatterjee, Final Year PGT, Department of Biochemistry, Medical College, Kolkata, West Bengal, India.

5 Prajna Sarkar, Second Year PGT, Department of Biochemistry, Medical College, Kolkata, West Bengal, India.

6 Indranil Chakrabarti, Second Year PGT, Department of Biochemistry, Medical College, Kolkata, West Bengal, India.
}

Background: Adenosine deaminase (ADA) is suggested to modulate the bioactivity of insulin, but its clinical significance in Type 2 diabetes mellitus (DM) is not yet established. The present study was undertaken to evaluate serum ADA activity and serum uric acid levels in patients of Type 2 DM. Aim: To evaluate the serum ADA level and to correlate ADA levels with Blood Glucose, Glycated Hemoglobin ( $\mathrm{HbA} 1 \mathrm{c}$ ) levels in Type-2 DM patients. Material and Method: It is a case control study. The subjects in this study were divided into 3 groups. Group I consisted of 50 normal healthy individuals who served as controls with no history of DM. Group II consisted of 50 patients of Type 2 DM both males \& females in the age group of 40-65 years on oral hypoglycemic drugs with $\mathrm{HbA} 1 \mathrm{c}$ $<7 \%$. Group III consisted of 50 patients of Type 2 DM both males \& females in the age group of $40-$ 65 years on oral hypoglycemic drugs with $\mathrm{HbA} 1 \mathrm{c}>7 \%$. Serum levels of fasting blood sugar, $\mathrm{HbA} 1 \mathrm{c}$, ADA and uric acid were estimated in all the subjects. Results: FBS, HbA1c, ADA and serum uric acid levels were found to be increased in the patients of Type 2 DM as compared with controls. Conclusion: It is concluded that there is an increase in serum ADA levels with increase in $\mathrm{HbA} 1 \mathrm{c}$ levels. Serum uric acid levels increased with moderately increasing levels of $\mathrm{HbA} 1 \mathrm{c}<7 \%$ and then decreased with further increasing levels of $\mathrm{HbA} 1 \mathrm{c}>7 \%$ (a bell-shaped relation).

Keywords: Type 2 Diabetes mellitus, Adenosine deaminase, Glycated Hemoglobin, Uric acid

Corresponding Author

Santanu Sen, Associate Professor, Department of General Surgery, Medical College, Kolkata, West Bengal, India.

Email: santanu.sen28@gmail.com
How to Cite this Article

Kundu D, Sen S, Paul A, Chatterjee A, Sarkar P, Chakrabarti I. Diagnostic value of serum adenosine deaminase in Type 2 diabetic patients. Int J Med Res Rev. $2019 ; 7(1): 1-7$.

Available From

https://ijmrr.medresearch.in/index.php/ijmrr/article/ view/1027
To Browse

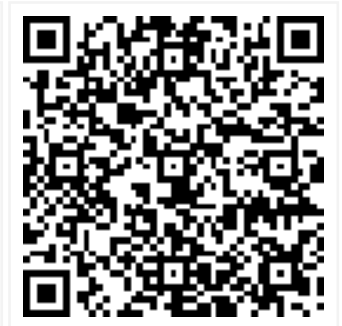

Manuscript Received 2018-11-09

Conflict of Interest No

Review Round 1
2018-11-30
Funding
Nil

Review Round 1

$\mathrm{Nil}$

$\begin{gathered}\text { Review Round } 2 \\ \text { 2018-12-04 }\end{gathered}$
$\begin{gathered}\text { Ethical Approval } \\ \text { Yes }\end{gathered}$

Review Round 3

Accepted 2018-12-07

Plagiarism X-checker $7 \%$

Note

(C) 2019 by Dipankar Kundu, Santanu Sen, Aniket Paul, Amrita Chatterjee, Prajna Sarkar, Indranil Chakrabarti and Published by Siddharth Health Research and Social Welfare Society. This is an Open Access article licensed under a Creative Commons Attribution 4.0 International License https://creativecommons.org/licenses/by/4.0/ unported [CC BY 4.0]. 


\section{Introduction}

Diabetes Mellitus (DM) is one of the most causative important factors of mortality in the developing countries where it affects more than 170 million people all over the world [1]. DM is a common endocrinological disorder characterized by absolute or relative deficiencies in insulin secretion and/or insulin action associated with chronic hyperglycemia and disturbances of carbohydrate, lipid, and protein metabolism [2].

Type-2 diabetes is characterized by insulin resistance where there is impaired ability of hormone to suppress hepatic glucose output and to promote peripheral glucose disposal and compromised function of pancreatic $\beta$-cells such that insulin secretion is insufficient to match the degree of insulin resistance. Also Immunological disturbances such as the cell mediated immune system and improper T-lymphocyte function play a role in the pathophysiology of T2DM [3].

Adenosine deaminase (ADA), an enzyme, which is present in red cells and the vessel wall catalyses the irreversible hydrolytic deamination of adenosine to inosine and 2'-deoxyadenosine to 2'-deoxyinosine. Inosine and 2'-deoxyinosine are converted to hypoxanthine, xanthine and finally to uric acid [4].

ADA is considered as a good marker of cell mediated immunity [5]. High lymphocyte ADA activities were found to be elevated in diseases in which there is cell mediated immune response [6]. It plays a crucial role in lymphocyte proliferation and differentiation, and shows its highest activity in T- lymphocytes [5]. Previously, adenosine deaminase has been reported to be a marker for insulin function [6].

But its connection with the immune system was not yet established in diabetic subjects. Even though there are some reports available on adenosine deaminase levels in diabetic subjects, these are all inconclusive. In a study, Hoshino $T$ et al [4] reported elevated ADA activity in the serum of Type 2 DM patients where as Angielski $S$ et al demonstrated that $5^{\prime}$-nucleotidase and ADA activities were not changed in isolated glomeruli of streptozocin diabetic rats[7].

Adenosine increases glucose uptake inside the cells. Thus, higher ADA activity will decrease adenosine levels and this in turn decreases glucose uptake into cells.
Thus, a suppression of ADA activity may help improve various factors associated with the pathophysiology of T2DM like insulin sensitivity and inflammation, cell proliferation and T-lymphocyte activity [4]. Moreover chronic hyperglycemia leads to increased oxidative stress by forming enediol radicals and superoxide ions by NADPH oxidase system and increases ADA levels, both leading to insulin resistance [5]. If activity of $A D A$ is suppressed, insulin sensitivity may be improved, and cellular proliferation, inflammation and T-cell activity which are associated with the pathophysiology of insulin resistance, can also be improved. Thus insulin resistance may have an important relationship with ADA activity [8]. Since a relationship exists between Adenosine Deaminase, cell mediated immunity and Type-2 Diabetes Mellitus, the present study was undertaken to determine Serum Adenosine Deaminase and serum uric acid levels in patients with Type 2 diabetes mellitus and to find correlation between blood glucose and Glycated Hemoglobin levels.

\section{Materials and Methods}

The study was conducted after obtaining usual permission from ethical committee, Medical College Kolkata and consent from cases and controls were taken before commencing the study.

Inclusion Criteria: The study population comprised of 50 normal healthy individuals both males and females in the age group of 40-65 years as controls in GROUP I, 50 patients of Type-2 DM both males and females in the same age group on oral hypoglycemic drugs with $\mathrm{HbA} 1 \mathrm{c}<7 \%$ in GROUP II and 50 patients of Type 2 DN age and sex matched on oral hypoglycemic drugs with $\mathrm{HbA} 1 \mathrm{c}>7$ $\%$ in GROUP III.

Exclusion Criteria: Neither of the subjects were on insulin treatment, nor did they have a history of infection or other ailments at the time of the study Patients with type 1 diabetes mellitus, acute complications of diabetes mellitus and history of acute infection or other ailments like gross congestive heart failure, tuberculosis, gout, rheumatoid arthritis, skeletal muscle injury and renal failure were excluded.

Subjects on insulin treatment, thiazolidinediones, glucocorticoids, thyroid hormones, thiazides, diazoxides, pentamidine, phenytoin, interferons or having a history suggestive of any infections, known complications of diabetes mellitus, liver disease, 
Immunological disorders, trauma or malignancy were excluded.

A complete clinical examination of subjects was done. About $5 \mathrm{ml}$ of fasting blood was collected for the determination of different biochemical parameters. The plasma obtained was analyzed for biochemical parameters such as fasting blood sugar (GOD-POD Method), serum adenosine deaminase (Erba), serum uric acid (uricase method) and glycated hemoglobin (immunoinhibition method), cholesterol, LDL-cholesterol, HDL-cholesterol, triglycerides, SGOT, SGPT, creatinine, total proteins and gamma glutamyl transferase. These were measured with the kits provided by Erba, Manheim, Germany.

\section{Determination of adenosine deaminase (ADA)-} The ADA levels were estimated using a commercially available kit (Erba, Manheim, Germany) [9]. The assay is based on the enzymatic deamination of adenosine to inosine which is converted to hypoxanthine by purine nucleoside phosphorylase (PNP). Hypoxanthine is then converted to uric acid and hydrogen peroxide by xanthine oxidase. Hydrogen peroxide is further reacted with $\mathrm{N}$-Ethyl-N- (2- hydroxy-3 sulf- opropyl) -3-methylaniline (EHSPT) and 4-aminoantipyrine in the presence of peroxidase to generate quinine dye which is monitored at $546 \mathrm{~nm}$. One unit of ADA is defined as the amount of ADA that generates one micromole of inosine from adenosine per min at $37^{\circ} \mathrm{C}$.

Statistical Analysis- The statistical analysis was performed using students' $\mathrm{t}^{\prime}$ test to compare mean values of variables in control and different groups of type 2 diabetes mellitus. The correlations were assessed by Pearson rank correlation coefficient.

Differences were considered statistically significant when $\mathrm{p}<0.05$ and highly significant when $\mathrm{p}<$ 0.001 .

\section{Results}

The sex and number distribution in both controls $(n=50)$, and cases $(n=100)$ shown in Table- 1 A.

The age, anthropometric measurements and blood pressure is depicted in Table $-1 B$.

Table-1A: Showing sex and number distribution

\begin{tabular}{|l|l|l|l|}
\hline Number & \multicolumn{1}{|c|}{$\begin{array}{c}\text { Group I } \\
(\mathrm{n}=\mathbf{5 0})\end{array}$} & $\begin{array}{c}\text { Group II } \\
(\mathrm{n}=\mathbf{5 0})\end{array}$ & $\begin{array}{c}\text { Group III } \\
(\mathrm{n}=\mathbf{5 0})\end{array}$ \\
\hline Male/Female (\%) & $60 / 40$ & $70 / 30$ & $50 / 50$ \\
\hline
\end{tabular}

Table-IB: Baseline characteristics of the participants.

\begin{tabular}{|c|c|c|}
\hline & $\begin{array}{c}\text { Mean } \pm \text { SD Controls, }(n \\
=50)\end{array}$ & $\begin{array}{c}\text { Mean } \pm \text { SD Subjects, }(\mathrm{n} \\
=\mathbf{1 0 0})\end{array}$ \\
\hline Age & $43.2 \pm 6.0$ & $44.0 \pm 5.1$ \\
\hline Height (cm) & $164 \pm 4.8$ & $169 \pm 6.0$ \\
\hline Weight (kg) & $61.8 \pm 7.5$ & $71.0 \pm 8.0$ \\
\hline \multicolumn{3}{|l|}{ Blood pressure } \\
\hline $\begin{array}{l}\text { a) Systolic (120 mm } \\
\mathrm{Hg})\end{array}$ & $118 \pm 4$ & $129 \pm 4$ \\
\hline $\begin{array}{l}\text { b) b. Diastolic ( } 80 \\
\text { mm Hg) }\end{array}$ & $76 \pm 5$ & $84 \pm 2$ \\
\hline
\end{tabular}

Table-2: Showing FBS \& Hb1AC In control and study groups.

\begin{tabular}{|l|l|l|l|l|l|l|}
\hline \multirow{2}{*}{$\begin{array}{l}\text { Group } \\
\mathbf{n}=50\end{array}$} & \multicolumn{3}{|c|}{ FBS } & \multicolumn{3}{|c|}{ HbA1C } \\
\cline { 2 - 7 } & Mean \pm & Comparison & p value & $\begin{array}{l}\text { Mean } \pm \\
2 \text { SD }\end{array}$ & Comparison & p value \\
\hline I. & $88.00 \pm 10$. & Gp I v/s Gp & $<0.001 *$ & $5.70 \pm 0.4$ & Gp I v/s Gp & 0.310 \\
II. & 00 & II & $* *$ & $0 \%$ & II & \\
& $129.18 \pm 21$ & Gp I v/s Gp & $<0.001 *$ & $6.10 \pm 0.4$ & Gp I v/s Gp & $<0.001 *$ \\
III. & 67 & III & $* *$ & $9 \%$ & III & $* *$ \\
& $137.04 \pm 20$ & Gp II v/s Gp & 0.114 & $8.90 \pm 1.0$ & Gp II v/s Gp & $<0.001 *$ \\
& .97 & III & & $2 \%$ & III & $* *$ \\
\hline
\end{tabular}

The mean FBS levels in Group I (88.00 \pm 10.00 $\mathrm{mg} / \mathrm{dl})$, Group II $(129.18 \pm 21.67 \mathrm{mg} / \mathrm{dl})$ and in Group III (137.04 $\pm 20.97 \mathrm{mg} / \mathrm{dl})$ respectively. In the present study, the mean FBS levels of Group II and Group III were found to be highly significantly higher than Group I ( $p<0.001$ ). Although the mean FBS levels of Group III were higher than Group II but the difference was statistically not significant $(p=0.114)$. The mean HbA1c levels in Group I $(5.70 \pm 0.40 \%)$, Group II $(6.10 \pm 0.49 \%)$ and in

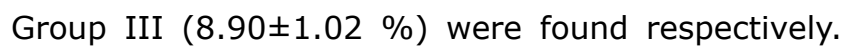
From this study it was observed that the difference in the levels of $\mathrm{HbA} 1 \mathrm{c}$ was found to be insignificant between Group II and Group I $(p=0.310)$ [Table-2].

Table-3: Comparison of ADA levels in three groups

\begin{tabular}{|l|l|l|l|}
\hline \multicolumn{1}{|c|}{ Group $(\mathbf{n = 5 0 )}$} & \multicolumn{1}{|c|}{ Mean \pm 2SD } & \multicolumn{1}{|c|}{ Comparison } & \multicolumn{1}{c|}{$\mathbf{p}$ value } \\
\hline I. & $17.30 \pm 7.08$ & Gp I v/s II & $<0.001$ \\
II. & $31.05 \pm 9.49$ & Gp I v/s III & $<0.001$ \\
III. & $44.03 \pm 15.10$ & Gp II v/s III & $<0.001$ \\
\hline
\end{tabular}

In the present study the mean serum ADA levels in Group I (17.30 $\pm 7.08 \mathrm{U} / \mathrm{L})$, Group II (31.05 \pm 9.49 $\mathrm{U} / \mathrm{L})$ whereas in Group III $(44.03 \pm 15.10 \mathrm{U} / \mathrm{L})$ were found respectively. 
Statistical analysis showed that the mean serum ADA levels of Group III were significantly higher than Group II $(p<0.001)$ and the levels of ADA were significantly higher in both Group II and Group III as compared to Group I $(p<0.001)$ [Table-3].

Table-4: Comparison of serum Uric Acid in three groups

\begin{tabular}{|l|l|l|l|}
\hline \multicolumn{1}{|c|}{ Group, $\mathbf{n = 5 0}$} & \multicolumn{1}{|c|}{ Mean \pm 2SD } & \multicolumn{1}{|c|}{ Comparison } & \multicolumn{1}{c|}{$\mathbf{p}$ value } \\
\hline A. & $6.29 \pm 1.58$ & Gp I v/s II & 0.383 \\
B. & $7.88 \pm 1.82$ & Gp I v/s III & 0.015 \\
C. & $5.20 \pm 1.29$ & Gp II v/s III & $<0.001 * * *$ \\
\hline
\end{tabular}

The mean serum uric acid levels in Group I $(6.29 \pm 1.58 \mathrm{mg} / \mathrm{dl})$, Group II $(7.88 \pm 1.82 \mathrm{mg} / \mathrm{dl})$ and in Group III $(5.20 \pm 1.29 \mathrm{mg} / \mathrm{dl})$ were found respectively. The mean serum uric acid levels of Group II were significantly higher than Group III $(p<0.001)$ whereas levels of mean serum uric acid in Group III were significantly lower than Group I $(p=0.015)$ but no significant difference was observed between Group I and Group II $(p=0.383)$ [Table-4].

Table-5: Comparison of serum ADA, Uric Acid and Hb1AC in Group II and Group III

\begin{tabular}{|l|l|l|l|l|l|}
\hline \multicolumn{2}{|c|}{ Parameter } & \multicolumn{2}{c|}{ Group I } & \multicolumn{2}{c|}{ Group II } \\
\cline { 3 - 6 } \multicolumn{2}{|l}{} & HbA1C & ADA & HbA1C & ADA \\
\hline ADA & r value & 0.003 & & 0.122 & \\
& p value & 0.908 & & 0.509 & \\
\hline Uric Acid & r value & 0.190 & 0.000 & -0.012 & 0.200 \\
& p value & 0.309 & 0.991 & 0.989 & 0.278 \\
\hline
\end{tabular}

The Pearson's correlation coefficient for the relationships between serum ADA, Uric acid and $\mathrm{HbA} 1 \mathrm{c}$ levels in Group II showed positive correlation between $\mathrm{HbA} 1 \mathrm{c}$ and ADA $(r=0.003)$. Similarly when the comparison was made between serum uric acid levels and $\mathrm{HbA} 1 \mathrm{c}$ there was positive correlation $(r=0.190)$ but when the comparison was made between serum ADA and uric acid there was no correlation $(r=0.000)$ [Table-5].

The Pearson's correlation coefficient for the relationships between serum ADA, Uric acid and HbA1c levels in Group III showed positive correlation between $\mathrm{HbA} 1 \mathrm{c}$ and ADA ( $r=0.122)$. When the comparison was made between serum uric acid levels and $\mathrm{HbA} 1 \mathrm{c}$ there was negative correlation $(r=-0.012)$ [Table-5].

Table-6: Biochemical parameters expressed in Mean $\mathbf{2 S D}$

\begin{tabular}{|r|l|l|}
\hline Parameters & \multicolumn{1}{|c|}{ Controls $(\mathrm{n}=\mathbf{5 0})$} & Subjects $(\mathrm{n}=\mathbf{1 0 0})$ \\
\hline Cholesterol $(\mathrm{mg} / \mathrm{dl})$ & $196.4 \pm 6.8$ & $210.4 \pm 6.8$ \\
\hline
\end{tabular}

\begin{tabular}{|l|l|l|}
\hline HDL Cholesterol (mg/dl) & $66 \pm 4.2$ & $61 \pm 4.2$ \\
LDL Cholesterol (mg/dl) & $110 \pm 9.8$ & $126.2 \pm 11.2 \mathrm{M}$ \\
Triglyceride (mg/dl) & $122.5 \pm 7.2$ & $143.2 \pm 6.8$ \\
SGOT (units/L) & $16.7 \pm 0.9$ & $22.1 \pm 1.6$ \\
SGPT (units/L) & $21.2 \pm 1.6$ & $17.2 \pm 1.4 \mathrm{M}$ \\
Creatinine (mg \%) & $0.67 \pm 0.06$ & $0.8 \pm 0.01$ \\
Total protein (g/dl) & $6.6 \pm 0.78$ & $7.2 \pm 0.9$ \\
\hline
\end{tabular}

The values of the biochemical parameters evaluated in the present study for both normal healthy individuals (control group) and type 2 diabetic subjects (cases) are represented in Table-6.

\section{Discussion}

In the present study, the mean serum ADA levels of group III were significantly higher than group II $(p<0.001)$. Also, the levels of ADA were significantly higher in both groups II and III than Group I $(p<0.001)$. Similar results were reported by and Kaur et al [10] \& Kurtal et al [11]. The pathogenesis of increased ADA levels in Type 2 D.M is explained by extra cellular CAMP - adenosine pathway. ADA inactivates adenosine and enhances lipolysis.

It also potentiates increase in CAMP accumulation. In the deficiency of insulin glucose circulate through blood and are taken up by Pancreas, to liver and adipose tissue. The adipocytes stores TAG (Triacylglycerol) leading to adipocyte hypertrophy. This exposure leads to cellular dysfunction, increased circulating FFA and a proinflammatory state. Exposure of Hepatocytes to excess fats and glucose leads to steatohepatitis and Insulin resistance.

Thus, there is elevation of free fatty acids in diabetes which leads to worsening of insulin resistance and $\beta$-cell dysfunction. Chronic Hyperglycemia leads to increased oxidative stress by forming enediol radical and super oxide ions with NADPH oxidase system and increases ADA levels both leading to Insulin resistance. GLUT4 receptors are down regulated in the absence of adenosine. This is one of the reasons for Insulin resistance.

Hyperglycemia leads to activation of NADPH oxidase, that catalyses $\mathrm{O}_{2}$ - formation by one electron reduction of $\mathrm{O} 2$ using $\mathrm{NADPH}$ or $\mathrm{NADH}$ as electron donor [12]. $2 \mathrm{O} 2+\mathrm{NADPH}($ or $\mathrm{NADH}) \rightarrow$ 2O2- + NADP (or NAD) + $\mathrm{H}+$ Another source of superoxide anion formation could be auto-oxidation of glucose which is subjected to enediol rearrangements that result in the formation of an enediol radical ion, which is capable of reducing molecular oxygen to form superoxide anion [13]. 
Hyperglycemia also causes formation of Advanced glycation End Products (AGEs) as result of nonenzymatic reactions between intra-cellular glucosederived dicarbonyl precursors with the amino group of both intracellular and extracellular proteins. The AGEs stimulate receptors for advanced glycation end products (RAGE). Their interaction is believed to initiate and aggravate the diabetic complications. In addition they increase the generation of reactive oxygen species in macrophages thereby causing oxidative stress [14].

Thus, increased adenosine deaminase activity leads to increased depletion of adenosine. Adenosine is both a metabolic precursor for nucleic acids and a significant signaling molecule involved in regulation of various physiological processes which linked to its localized release. Adenosine modulates the action of insulin on various tissues differently and its concentration in tissues is affected by ADA levels. It mimics the action of insulin on glucose and lipid metabolism in adipose tissue and the myocardium.

Adenosine potentiated insulin and contraction stimulated glucose transport in skeletal muscles by enhancing the increase in GLUT-4 at the cell surface. A1 receptor agonists of adenosine have been found to be associated with increased insulin sensitivity. Thus, depletion of adenosine due to increased adenosine deaminase activity would mean increase in insulin resistance in the body \& subsequent hyperglycemia, which is a hallmark feature of diabetes mellitus [12].

AGEs bind to AGE receptors on several cell types (endothelial cells, mesangial cells and macrophages) and lead to release of cytokines; TNF-a, IL-1, IL-6 and growth factor from macrophages and mesangial cells resulting in activation of T lymphocytes [15].

ADA plays a crucial role in lymphocyte proliferation and differentiation and shows its highest activity in T-lymphocytes [16]. High ADA activity might be due to abnormal T-lymphocyte responses or proliferation and may point to a mechanism that involves its release into circulation. Therefore, in the present study, we report that increased ADA activity in diabetic individuals could be due to altered insulin related T-lymphocyte function. Singh P. et al in 2013 also studied the activity of ADA in type 2 diabetes mellitus and reveals that increase in serum ADA levels was associated with increase in $\mathrm{HbA} 1 \mathrm{c}$ levels, which may play an important role in determining the glycemic status in diabetes [17].
The reason for increased uric acid levels could be due to increased activity of ADA, an enzyme responsible for converting adenosine to uric acid in patients of type 2 Diabetes Mellitus.

Another reason behind the increase in serum uric acid levels could be due to hyperinsulinemia in insulin resistant individuals. Studies showed that Insulin can stimulate the urate-anion exchanger or the Na-dependent anion co-transporter in brush border membranes of the renal proximal tubule and increase renal urate reabsorption [13]. However, a negative correlation of uric acid in poor glycemic status may be related to the inhibition of uric acid reabsorption in the proximal tubule by high glucose levels in diabetic individuals.

The correlation between serum ADA and $\mathrm{HbA} 1 \mathrm{c}$ levels in Group II \& Group III revealed that there is positive correlation between $\mathrm{HbA} 1 \mathrm{c}$ and $\mathrm{ADA}$ and this shows with the increase in glycated haemoglobin levels, levels of serum ADA also increases. This positive correlation between ADA level with short and long term glycemic control suggest its important role in glucose and lipid metabolic derangements seen in type 2 DM patients. This finding was similar with the study done by Kurtul et al [11], Singh et al [17] and Ramani et al [18].

However, this study has a few limitations. A concomitant lymphocytic/plasma adenosine deaminase and its activity on insulin or vice versa, and a correlation with oral glucose tolerance test (OGTT) are to be carried out to strengthen this concept.

\section{Conclusion}

In the present study, significantly higher values of ADA in cases compared with controls suggest that ADA plays a role in pathophysiology of type 2 DM ant its complications. A positive correlation between ADA level with good and poor glycemic control suggests its important role in modulating the bioactivity of insulin. Thus, increased activity might be a marker for insulin resistance.

Therefore, estimation of serum ADA might serve as a glycemic marker for assessing the glycemic status of a diabetic patient. The serum uric acid levels were found with moderately increasing levels of $\mathrm{HbA} 1 \mathrm{c}<7 \%$ and then decreased with further increasing levels of $\mathrm{HbA} 1 \mathrm{c}>7 \%$. 
Larger and more elaborated studies are required including ADA, insulin, immunological markers and also at molecular levels to know the role of ADA in the pathogenesis of Type-2 DM and its complications.

\section{Acknowledgement}

We would like to thank the management of medical college.

\section{Reference}

01. Nathan DM. DCCT/EDIC Research Group, The diabetes control and complications trial/ epidemiology of diabetes interventions and complications study at 30 years- overview. Diabetes Care. 2014;37(1)9-16.

doi: $10.2337 / \mathrm{dc} \quad 13-2112$ [Crossref]

02. Bobb A, Gale D, Manmohan S, et al. The impact of the chronic disease assistance plan (CDAP) on the control of type 2 diabetes in Trinidad. Diabetes Res Clin Pract. 2008 Jun;80(3)360-4. doi: 10.1016/j.diabres. 2007. 11.010 [Crossref]

03. Vineet Kumar Khemka, Debajit Bagchi, Arindam Ghosh, Oishimaya Sen, Aritri Bir, Sasanka Chakrabarti, and Anindita Banerjee. Raised Serum Adenosine Deaminase Level in Nonobese Type 2 Diabetes Mellitus. The Scientific World Journal. 2013;1-5.

[Crossref]

04. Hoshino T, Yamada K, Masuoka K, et al. Elevated adenosine deaminase activity in the serum of patients with diabetes mellitus. Diabetes Res Clin Pract. 1994 Sep;25(2)97-102. [Crossref]

05. Sullivan JL, Osborne WR, Wedgewood RJ. Adenosine deaminase activity in lymphocytes. $\mathrm{Br}$ J Haematol. 1977 Sep;37(1)157-8. [Crossref]

06. Prakash MS, Chennaiah S, Murthy YSR, et al. Altered adenosine deaminase activity in Type 2 diabetes mellitus. JIACM. 2006;7(2)114-117. [Crossref]

07. Angielski S, Jakubowski Z, Pawelczyk T, et al. Renal handling and metabolism of adenosine in diabetic rats. Contrib Nephrol. 1989;73;527; discussion 57-8. [Crossref]
08. Lee JG, Kang DG, Yu JR, et al. Changes in Adenosine Deaminase Activity in Patients with Type 2 Diabetes Mellitus and Effect of DPP-4 Inhibitor Treatment on ADA Activity. Diabetes Metab J. 2011 Apr;35 (2)149-58. doi: $10.4093 / \mathrm{dmj} .2011 .35 .2 .149$ [Crossref]

09. Delacour H, Sauvanet C, Ceppa F, et al. Analytical performances of the Diazyme ADA assay on the Cobas $\AA 6000$ system. Clin Biochem. 2010 Dec;43(18)1468-71. doi: 10.1016/j.clinbiochem. 2010.09.005 [Crossref]

10. Amandeep Kaur, SahibaKukreja, Naresh Malhotra, Neha. Serum Adenosine Deaminase Activity and Its Correlation with Glycated Haemoglobin Levels in Patients of Type 2 Diabetes Mellitus. Journal of Clinical and Diagnostic Research. 2012 April;6(2)252-256. [Crossref]

11. Kurtul N, Pence S, Akarsu E, et al. Adenosine deaminase activity in the serum of type 2 diabetic patients. Acta Medica (Hradec Kralove). 2004;47(1)33-5.

[Crossref]

12. Singh PP, Mahadi F, Roy A and Sharma $P$. Reactive oxygen species, reactive nitrogen species and antioxidants in etiopathogenesis of diabetes mellitus type -2 . Indian Journal of Clinical Biochemistry. 2009;24(4)324-342. [Crossref]

13. Enomoto $A 1$, Kimura $H$, Chairoungdua $A$, et al. Molecular identification of a renal urate anion exchanger that regulates blood urate levels. Nature. 2002 May 23;417(6887)447-52. [Crossref]

14. Ahmed N. Advanced glycation endproducts-role in pathology of diabetic complications. Diabetes Res Clin Pract. 2005 Jan;67(1)3-21. DOI: $10.1016 /$ j.diabres.2004.09.004

[Crossref]

15. Goldsby RA, Kindt TJ, Osborne BA. CytokinesKuby immunology. 4th ed, New York- WH Freeman and Company. 2000;320. [Crossref]

16. Hovi T, Smyth JF, Allison AC, et al. Role of adenosine deaminase in lymphocyte proliferation. Clin Exp Immunol. 1976 Mar;23(3)395-403.

[Crossref] 
17. Priti Singh, Salman Khan, Mittal Rabindra Kumar. Adenosine deaminase activity and its relation with glycated hemoglobin and uric acid in type 2 diabetic patients. Iranian Journal of Diabetes and Obesity. 2013;(5)1-6.

[Crossref]
18. Ramani Nisha Subash Chandra, Krishna Murthy $\mathrm{N}$, Raghavendra Prasad BN et al. Role of Adenosine Deaminase to Predict Glycemic Status in Type 2 Diabetes Mellitus. J clin Biomed Sci. $2012 ; 2 ; 23-132$.

[Crossref] 